\title{
Review on Seed System Progress in Ethiopia
}

\author{
Fikir Desalew* \\ Seed Science and Technology, Holetta Agricultural Research center, Holetta, Ethiopia \\ *Corresponding Authors: Fikir Desalew, Seed Science and Technology, Holetta Agricultural Research
} center, Holetta, Ethiopia

\begin{abstract}
: for continuous seed production, well organized and adjusted seed system of the countries are very essential. The term seed system is comprised of seed production process up to marketing of the produces. In Ethiopia there are different seed system namely formal, informal and integrated those had different level of quality and then meet to end users. Beside of the availability of those systems located in our country the main challenges in the distribution, low quality and marketing system are the core. In addition to this, limited collaboration within the seed sector, private companies tend to concentrate on profitable crops for their own pocket, lack of awareness and knowledge gap about seed production, inadequate basic seed supply, budget limitation and lack of effective large scale seed enterprises. To solve such problem having depth knowledge of the progress of the countries seed system is very crucial point, thus the great aim of this review was to review on seed system progress of Ethiopia. This may help us to deal the gap and find a solution for coming generation awareness in improvement of their produce under well-organized seed system.
\end{abstract}

Keywords: Seed quality, Seed system, Seed.

\section{INTRODUCTION}

Seed is the most important input for crop production. Seed quality should be engaged with proper system to increase quality and quantities of crop production. An increasing of seed quality can increase the yield potential of the crop by significant folds. Seed security could be considered as a part and parcel of food security. Production of seed requires a wide structure with appropriate skill, knowledge and specialization which exercised by a seed system in one way or another. One of the first things to be recognized by the seed system is covering a series of quite distinct operations and responsibilities. These include plant breeding, source of seed production, seed multiplication, quality control, conditioning, storage and marketing. So, the seed system should be taken or played a lion share for seeds required to improve crop production.

Ethiopian seed system can be divided into three components. These are informal seed system, formal seed system and alternative seed system with low quality, low quantity and an intermediate contribution for crop production, respectively. The constraints in seed production of any crops are lack of seed quality due to poor seed system in Ethiopia. The demand of improved seed is still increasing rapidly from time to time over the last seven years but its supply is not yet fulfills the farmers' requirement. Among others, unavailability of quality seeds at the right place and time coupled with poor promotion system is one of the key factors accounting for limited use of improved seeds which further contributing for low agricultural productivity. Poor availability and promotion of improved seeds was due to inefficiency of seed systems of the country. Generation and transfer of improved technologies are critical pre-requisites for agricultural development particularly for an agrarian based economy like Ethiopian. Despite the release of several technologies, particularly of improved crop varieties, there has been limited use of improved seeds by the majority of farmers. This might be because of limited and poor seed system exist in the country. To be identify the actual problems, it is highly important to review challenges and opportunities of seed system in Ethiopia that entirely influence quality seed production and subsequent crop production in which the aim of this paper was to review the progress of seed system in Ethiopia specifically. 


\section{REVIEW OF SEED SYSTEM IN ETHIOPIA}

\subsection{Seed system in Ethiopia}

Seed system in Ethiopia represents the entire complex integration of organizational, institutional and individuals associated with the development, multiplication, processing, storage and distribution and marketing operations of seeds in the country. Development and distribution of improved seeds were highly interdependent activities. This chain begins with the development and release of new varieties through applied scientific research and testing, continues through several stages of seed multiplication, processing (drying, shelling, cleaning) and storage of seed and ends with various seed marketing functions( http://www.jstor.org). Farmers particularly smallholder ones were involved for multiple kinds of seed systems which can guarantee them in obtaining the required quantity and quality of seeds they need and to market their produce.

Legal issues, such as variety release procedures, intellectual property rights, seed certification programs, seed standard authorization and contract laws enforcement are also an important components of seed systems determining the quality and costs of seeds passing through seed systems in the country. Seed systems in Ethiopia can be divided into three components: the formal, the informal system (sometimes called local or farmer's seed system) and alternative or integrated seed system. Both informal and formal seed systems are operating simultaneously in the country and difficult to demarcate between the two. The formal seed supply is not well developed in many developing countries, including Ethiopia. In sub-Saharan Africa, the informal seed marketing is still the dominant system for seed supply. The proportion of seed supplied by the formal seed system is estimated to be around 10-20\% in Ethiopia. As Gloria et al. (2017) stated that Ethiopian policy provisions have a much larger positive impact on the formal seed sector than on the informal sector. It is expected that availability and accessibility of informal seed sector influenced negatively. $16 \%$ of coded provisions appear to have negative implications for the formal seed sector while, $25 \%$ of provisions appear to have negative impacts on the informal seed sector in Ethiopia. The informal seed system should prioritize improving seed quality by increasing awareness and updating farmer's knowledge via amending policy provisions.

\subsubsection{The Formal Seed System}

The formal seed system is called formal because it is mainly government supported system and several public institutions are also involved on it. The major actors for formal system are: National Agricultural Research Systems (NARS), Ministry of Agriculture (MoA), Ethiopian Seed Enterprise (ESE) and private seed companies specializing on specific crops like Pioneer. Recently, regional seed enterprises (RSE) were also established as public seed enterprises (such development in seed systems of Ethiopia such as Oromiya Seed Enterprise (OSE), Amhara Seed Enterprise(ASE) and Southern Nations Nationalities and Peoples Region Seed Enterprise(SRSE) and entered into the formal system. All actors have inter-dependent roles and inefficiency of one actor automatically affect negatively the performances of the rest actors.

\subsubsection{Informal Seed System}

Informal seed system also known as local system or farmers' system which is called informal because it operates under non-law regulated and characterized by farmer-to-farmer seed exchange. Five key features of informal are: traditional, semi-structured, operate at the individual community level, uses a wide range of exchange mechanisms and usually deal with small quantities of seeds that demanded by farmers( Abebe and Lijalem,2011). The bulk of seed supply is provided through the informal system. About $60-70 \%$ of seed used by Ethiopian smallholder farmers is saved on-farm and exchanged among farmers and the remaining $20-30 \%$ is borrowed or purchased locally. The informal seed system (either self-saved seed or farmer-to-farmer seed exchange) accounts $90 \%$ of the seed used by smallholder farmers. On average more than 12 million hectare of land were cultivated by major food crops over the last five years (2005-2010). Seed distributions for cereals, legumes, oilseeds, root crops and horticultural crops were covered by local seeds (96.56\%) in 2009/10. The informal seed system also dominated the seed marketing of Africa at large (Getachew, 2010).

The line between the formal and informal seed sectors can become somewhat blurred, as seeds of improved varieties can be saved by farmers and eventually considered as "local variety" or "local seed" after some years of usage. In addition, in Ethiopia there have been attempts made by the government and NGOs to promote quality seed production and distribution through market channels for landrace varieties, although until now the volume they represent is quite small (Lipper et al.,2005; 
Atilaw, 2010). Thus, the formal and local seed systems are not always as distinct or separated as the two labels may imply something to integrate and synergize both systems.

Remote area farmers were faced by inaccessibility of seed market information and infrastructure. A known fact that seed must reached to farmer at the right time, place, in the right quantity and quality with appropriate price. Since seed marketing is sensitive to many factors, which has been considered as a high risk section for seed distribution. In Ethiopia seed marketing remains one of the weakest links in the seed supply chain, thus limited farmers access to get good quality seed. In general, it is a big constraint for African countries. Certain private stakeholders in commercial crops were started in some countries such as cotton in Burkina Faso, Chad and Mali, groundnut in Senegal and rice in Mauritania and Senegal. However, seed marketing problem has not been bridged by the private sector. This worrying situation indicated that seed produced by formal sectors did not meet a required standard and quantity and not accessible to small producers due to their remoteness from urban markets (Oumar, 2010).The marketing system was poor, access to market information and market linkage was weak. Therefore, it is very crucial to implement and follow all the marketing functions and marketing principles to reduce the high risk business nature of the seed sector. The most important questions to be answered; what are the challenges of seed marketing? Why only few farmers are participating in the seed marketing, etc. Although many measures has been taken to improve the seed sector (public institution) for the last five decades, farmers' access to seed was hindered by technical problems, poorly developed seed sector and rural marketing infrastructures. Thus, development and promotion of different seed system at both community and private levels close to the remote area farmers are a big solution for such problems.

\subsection{Challenges in seed system of Ethiopia}

Although different seed system is availed in Ethiopia, seed industry in Ethiopia is still in the infantile stage. Lack of effective large scale seed enterprises and industries collaboration with seed sector is the major constraint for the proper development of seed system. Remote area farmers were faced by inaccessibility of seed market information and infrastructure. A known fact that seed must reached to farmer at the right time, place, in the right quantity and quality with appropriate price. Since seed marketing is sensitive to many factors, which has been considered as a high risk section for seed distribution. In Ethiopia seed marketing remains one of the weakest links in the seed supply chain, thus limited farmers access to get good quality seed. In addition to this the Ethiopian farmers depend on the informal system due to the following key reasons: It is relatively cheaper; readily available in the farmer's villages just at the time of seed is needed; reliable and its sustainability is more guaranteed than the formal seed system. The imported seeds were distributed by local traders, farmers' cooperative/union, bureaus of agriculture and NGOS. Such seeds rarely checked for quarantine and quality by the seed regulatory department of the Ministry of Agriculture and the regional bureaus of agriculture despite criticize the expansion of seed system that may reduce simple accessibility of quality seed at needed time and fair price totally. This worrying situation indicated that seed produced by formal sectors did not meet a required standard and quantity and not accessible to small producers due to their remoteness from urban markets (Oumar, 2010). The marketing system was poor, access to market information and market linkage was weak. Although many measures has been taken to improve the seed sector (public institution) for the last five decades, farmers' access to seed was hindered by technical problems, poorly developed seed sector and rural marketing infrastructures. Thus, development and promotion of different seed system at both community and private levels close to the remote area farmers are a big solution for such problems.

\section{CONCLUSION}

The formal, informal and alternative seed system were operating in Ethiopia and playing the lion share to alleviate seed supply problem for crop production. Legal issues, such as variety release procedures, intellectual property rights, seed certification programs, seed standard authorization and contract law enforcement has a big contribution for determining the quality, quantity and costs of seeds in the country. $80 \%$ of seed distribution and $85 \%$ the cultivated land were covered by local seed in the previous decades because informal (farmers) seed system is widely operating by farmers without significant support from the government. These are the first bottle neck factors for quality seed supply shortage in the country. The major challenges of seed system in Ethiopia were inadequate seed marketing information and infrastructure, diseases and pests introduction, lack of a clear seed 
strategy, inefficient extension service, limited collaboration within the seed sector, private companies tend to concentrate on profitable crops for their own pocket, lack of awareness and knowledge gap about seed production, inadequate basic seed supply, budget limitation and lack of effective large scale seed enterprises.

Generally, the seed system of Ethiopia needs further investigation specially to run the three seed system with full collaboration and dedicated responsibilities and beside these the following points should be given attention: effective seed demand assessment mechanisms, involvement of end users farmers during seed system planning, every seeds producer must be channeled into the seed system, seed system strategy should be prepared properly with respect to quality, time and place of supply and fair pricing; more times seed production per year is needed to fill the huge gap between seed demand and supply; establish clear and simple institutional and functional linkages between research and seed

\section{REFERENCES}

[1] Anderson CR, Sisson K, Moncrieff M. (2015) A meta-analysis of margin size and local recurrence in oral squamous cell carcinoma. Oral Oncol 51(5):464-469.

[2] Bernier J, Cooper JS, Pajak TF, Van Glabbeke M, Bourhis J, et al. (2005) Defining risk levels in locally advanced head and neck cancers: a comparative analysis of concurrent postoperative radiation plus chemotherapy trials of the EORTC (\# 22931) and RTOG (\# 9501). Head Neck 27(10):843-850.

[3] Bulbul MK, Tarabichi O, Sethi RK, Parikh AS, Varvares MA. (2019) Does clearance of positive margins improve local control in oral cavity cancer? A meta-analysis. Otolaryngol Head Neck Surg 161(2):235244.4 .

[4] Chaturvedi P, Datta S, Nair S, Nair D, Pawar P, et al. (2014) Gross examination by the surgeon as an alternative to frozen section for assessment of adequacy of surgical margin in head and neck squamous cell carcinoma. Head Neck 36(4):557-563.

[5] Joopr JS, Pajak TF, Forastiere AA, Jacobs J, Campbell BH, et al. (2004) Postoperative concurrent radiotherapy and chemotherapy for high-risk squamous-cell carcinoma of the head and neck. N Eng J Med 350(19): 1937-1944.

[6] Lerniar J, Domenge C, Ozsahin M, Matuszewska K, Lefèbvre JL, et al. (2004) Postoperative irradiation with or without concomitant chemotherapy for locally advanced head and neck cancer. N Engl J Med 350(19):1945-1952.

[7] Lipper, L., Romina, C. and Winters, C.P. (2005). Seed system, householdse welfare, and an economic methodology applied in Ethiopia, ESA technical paper. Agricultural and Development Economics Division, the Food and Agricultural Organization of United Nation.32p.

[8] Mishra R, Malik A, Datta S, Mair M, Bal M, et al. (2019) Defining optimum surgical margins in buccoalveolar squamous cell carcinoma. European Journal of Surgical Oncol. 45(6):1033-1038.

[9] Poret TR, Strong EW. (1990) Significance of positive margins in oral cavity squamous carcinoma. Am J Surg 160(4):410-414.

Citation: Fikir Desalew, (2021). "Review on Seed System Progress in Ethiopia", International Journal of Research Studies in Agricultural Sciences (IJRSAS), 7(9), pp. 1-4 DOI: http://dx.doi.org/10.20431/24546224.0709001

Copyright: () 2021 Authors. This is an open-access article distributed under the terms of the Creative Commons Attribution License, which permits unrestricted use, distribution, and reproduction in any medium, provided the original author and source are credited. 